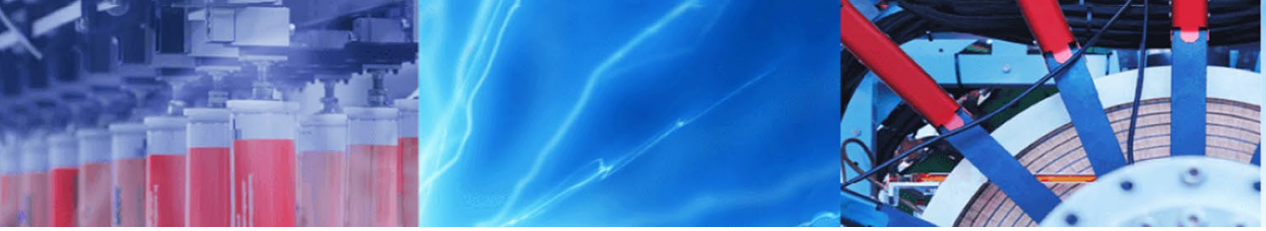

Research Article

\title{
Phyto-mediated synthesis of zinc oxide nanoparticles using aqueous plant extract of Ocimum americanum and evaluation of its bioactivity
}

\author{
H. K. Narendra Kumar ${ }^{1} \cdot$ N. Chandra Mohana ${ }^{1}$ - B. R. Nuthan ${ }^{1} \cdot$ K. P. Ramesha ${ }^{1} \cdot$ D. Rakshith ${ }^{1} \cdot$ N. Geetha ${ }^{2}$. \\ Sreedharamurthy Satish ${ }^{1}$
}

(c) Springer Nature Switzerland AG 2019

\begin{abstract}
Bionanotechnology has gained wide attention in the research field of modern materials science over the past decade. Biogenic synthesis of zinc oxide nanoparticles ( $\mathrm{nnO} \mathrm{NP}$ ) has been focused by researchers due to their non-toxicity and a broad range of applications. In the present work, spherical shape nanoparticles (average $21 \mathrm{~nm}$ size) were obtained using plant extract of Ocimum americanum. The biosynthesized ZnO NPs showed a strong absorption peak at $316 \mathrm{~nm}$ which is a characteristic feature of ZnO NPs. Further, biophysical characterization of synthesized ZnO NPs was carried out using Fourier transform infrared spectroscopy in comparison with plant extract to determine the possible functional groups involved in ZnO NPs formation, X-ray diffraction and confirmed the crystalline nature which is in accordance with JCPDS ID for ZnO NPs, scanning electron microscopy and dynamic light scattering for shape and size. Evaluation of antimicrobial efficacy of the biosynthesized ZnO NPs was found to be significant against four Gram-positive, four Gram-negative bacteria and two human pathogenic fungi. These results affirm that plant mediated ZnO NPs are potential for effective antioxidant and antimicrobial therapeutics.
\end{abstract}

Keywords Phyto-mediated $\cdot$ Zinc oxide nanoparticles $\cdot$ Ocimum americanum $\cdot$ Antioxidant $\cdot$ Antimicrobial

\section{Introduction}

Bionanotechnology has been extensively focused in the past decade. The metal oxide nanoparticles have been promising source owing to their extremely small size and large surface area [1-3]. Metal oxides owing to their difference in electronic structure exhibit metallic, semiconductor and insulator character along with biological activities [4-9]. The preparation of metal oxide nanostructures can be employed through both physical and chemical methods. Among these, sol-gel synthesis [10-12] and green synthesis [13-20] for fabrication has been extensively studied by researchers in material sciences. These metal oxides NPs have a wide range of properties such as optical, thermal, catalytic, optoelectronic, mechanical, magnetic, electrical, photochemical and biological activities making them excellent candidates for various applications. The metal oxide NPs have various applications in the field of medicine and different strategies have also been adopted for synthesizing nanoparticles such as organometallic synthesis, pyrolysis, thermal evaporation, microwave methods, mechanical milling and biosynthesis using organisms [21-24]. Among the metal oxide synthesis technique, the biological synthesis is due to its non-toxicity, low cost and eco -friendly. Zinc oxide has been attractive to researchers, because of its characters features such as biosafety, susceptibility to microorganisms, electrical and thermal properties. ZnO NPs have shown considerably high activity compared to $\mathrm{CaO}$ and $\mathrm{MgO}[21,22]$. Furthermore, it is non-toxic, compatible with the skin and

$\triangle$ Sreedharamurthy Satish, satish.micro@gmail.com | ${ }^{1}$ Microbial Drugs Laboratory, Department of Studies in Microbiology, University of Mysore, Manasagangotri, Mysore, Karnataka 570006, India. ${ }^{2}$ Department of Studies in Biotechnology, University of Mysore, Manasagangotri, Mysore, Karnataka 570006, India. 
used in many dermatological applications. Many reports have suggested that ZnO NPs interfere in membranes of prokaryotes there by breaking the integrity of membranes eventually leading to bacterial death [25-31]. Nanoparticles penetrate the bacterial cells thereby producing reactive oxygen species which damages the DNA, cell membranes and cell proteins which inhibits the growth and development of bacterial cell and leading to death $[26,27$, 52]. Biosynthesized ZnO NPs have been reported in previous studies to possess significant inhibition against both bacterial as well as fungal pathogens when compared with chemically synthesized nanoparticles [30].

Ocimum americanum L. (Lamiaceae) also known as American basil or hoary basil. It is a traditional medicinal plant which is distributed throughout India [32, 33]. The plant is mainly known for its medicinal aspects and is used in treatment of dysentery, skin diseases, fever, coughs, cold, diabetes, indigestion, diarrhoea, toothache, migraine and also against bacterial and fungal infections [32-35]. The present investigation is the first report on biosynthesis of $\mathrm{ZnO} N P s$ synthesized using Ocimum americanum, since this plant extracts are previously reported as considerable bioactivity. Therefore, ZnONP's were characterized by scanning electron microscope (SEM), X-ray powder diffraction (XRD) and Fourier-transform infrared spectroscopy (FTIR) techniques. Hence, owing to its ethnomedicinal values the present investigation has been undertaken to evaluate bioactive potential of biosynthesized ZnONPs from aqueous extract of Ocimum americanum.

\section{Materials and methods}

\subsection{Plant collection site}

Specimens of Ocimum americanum was collected from Mysuru, Karnataka, India ( $12.26^{\circ} \mathrm{N} 76.6^{\circ} \mathrm{E}$, Elevation $\left.763 \mathrm{~m}\right)$. The plant was authenticated by Botanical taxonomist from Department of Studies in Botany, University of Mysore, Manasagangotri, Mysore, Karnataka, India.

\subsection{Preparation of Ocimum americanum plant leaf extract}

Fresh asymptomatic plant of Ocimum americanum was thoroughly washed with running tap water followed by double sterile distilled water for removing particulate dust material from the plant surface. The shade dried plant samples were crushed into a fine powder using a blender. Further, $10 \mathrm{~g}$ of fine powdered plant material was mixed in $100 \mathrm{ml}$ of nanopure water and subjected to water bath at $60^{\circ} \mathrm{C}$ for $15 \mathrm{~min}$. The extract was filtered with Whatman No.1 filter paper for the synthesis of zinc oxide nanoparticles [26].

\subsection{Synthesis of zinc oxide nanoparticles}

Zinc nitrate hexahydrate $(1 \mathrm{Mm})$ of $10 \mathrm{~mL}$ solution was dissolved in $90 \mathrm{ml}$ of a prepared plant extract with nanopure water and kept in water bath at $60^{\circ} \mathrm{C}$ for $1 \mathrm{~h}$. The color change was observed confirming the reaction after $1 \mathrm{~h}$ of incubation time. The solution was later centrifuged at $8000 \mathrm{rpm}$ at room temperature (RT) for $15 \mathrm{~min}$ and the pellet was collected. The pellet obtained was subjected for repeated centrifugation thrice suspended with nanopure water, later air dried at RT for $2 \mathrm{~h}$ and preserved for further studies [36, 37].

\subsection{Characterization of zinc oxide nanoparticles}

The synthesized zinc oxide nanoparticles were characterized by UV-Vis spectroscopy (DU739, Beckman Coulter, Germany) with operating resolution of $1 \mathrm{~nm}$ from 200 to $600 \mathrm{~nm}$; Dynamic Light Scattering (DLS) Analysis (Microtrac, USA); Fourier Transform Infra-Red (FT-IR) Spectroscopy (Perkin Elmer Spectrum Two); X-ray diffraction (XRD) analysis (Rigaku Desktop Miniflex II X-ray powder diffractometer) and Scanning electron microscopic (SEM) (HITACHI S-3400 N, Japan).

\subsection{Anti-oxidant activity}

The antioxidant activity of biosynthesized ZnO NPs were determined using DPPH method. $100 \mu \mathrm{l}$ of DPPH solution (dissolved in methanol) was displaced in 96 well plates. $50 \mu \mathrm{l}$ of $\mathrm{ZnONPs}$ with concentration ranging from $1,0.5,0.25$ to $0.125 \mathrm{mg} / \mathrm{mL}$ was added and the mixture was incubated at RT for 20 min along with Ascorbic acid as a reference standard for determining antioxidant activity [27]. The absorbance of samples was measured at $517 \mathrm{~nm}$ followed by DPPH scavenging activity was calculated using the below equation.

Scavenging activity $(\%)=\left[\left({ }^{\mathrm{A}} \mathrm{DPPH}-{ }^{\mathrm{A}} \mathrm{s}\right) /{ }^{\mathrm{A}} \mathrm{DPPH}\right] \times 100$ 
where ${ }^{A} \mathrm{DPPH}$ is absorbance without sample and ${ }^{\mathrm{A}} \mathrm{s}$ the absorbance in the presence of the samples. Ascorbic acid was used as the standard antioxidant.

\subsection{Antimicrobial activity}

Antimicrobial susceptibility test against human pathogenic bacteria and fungi was carried out by disc diffusion method [14]. The test microorganisms Bacillus cereus (MTCC 430), Klebsiella pneumonia (MTCC 7407), Staphylococcus aureus (MTCC 7443), Vibrio parahaemolyticus (MTCC 451), Escherichia coli (MTCC 7410), Pseudomonas aeruginosa (MTCC 7903), Salmonella typhi (MTCC 733), Xanthomonas citri (MTCC 7908), Candida albicans (MTCC 183), Aspergillus parasiticus (MTCC 2796) were procured from Microbial Type Culture Collection (MTCC), Chandigarh, India. The sterile discs $(6 \mathrm{~mm})$ impregnated with fabricated ZnONP's (50 $\mu \mathrm{g} / \mathrm{disc}$ ) were placed on Muller-Hinton agar (MHA), Sabouraud Dextrose Agar (SDA) medium seeded with test bacteria and fungi, respectively. Zinc nitrate hexahydrate (1 $\mathrm{mM} /$ disc) served as assay control, Gentamicin $(10 \mu \mathrm{g} / \mathrm{disc})$ as a positive control for bacteria and Nystatin $(100 \mu \mathrm{g} / \mathrm{disc})$ for fungi. The plates were then incubated at $37 \pm 2{ }^{\circ} \mathrm{C}$ for bacteria, $25 \pm 2^{\circ} \mathrm{C}$ for fungi and zone of inhibition was recorded $[26,30]$.

\subsection{Live and dead cell analysis}

The live and dead cell was performed by treatment of test bacteria E. coli and Staph. aureus $\left(1.5 \times 10^{8} \mathrm{CFU} \mathrm{mL}^{-1}\right)$ with ZnO NPs $(50 \mu \mathrm{g})$, Gentamicin (10 $\mu \mathrm{g} /$ disc) and untreated cells as control for $24 \mathrm{~h}$ at $37 \pm 2{ }^{\circ} \mathrm{C}$. After incubation the cells were centrifuged at $10,000 \mathrm{rpm}$ for $10 \mathrm{~min}$, followed by pellet wash using phosphate buffer saline (PBS) solution. The bacterial cell samples were mixed with fluorescent dye solution of ethidium bromide $(\mathrm{EB})$ and acridine orange (AO) at 1:1 ratio allowed to stand for $30 \mathrm{~min}$ [26]. Followed by resuspension with $10 \mu \mathrm{l}$ of PBS solution, the solution was air-dried in a clean microscopic glass slide and examined using a Fluorescence microscope (Lawrence and Mayo, Germany; excitation filter 430 to $470 \mathrm{~nm}$ at $100 \times$ magnification).

\subsection{Statistical analysis}

Data from three replicates were analyzed for each experiment and analysis of variance (ANOVA) using IBM SPSS Version 25.0. Significant effects of treatments were

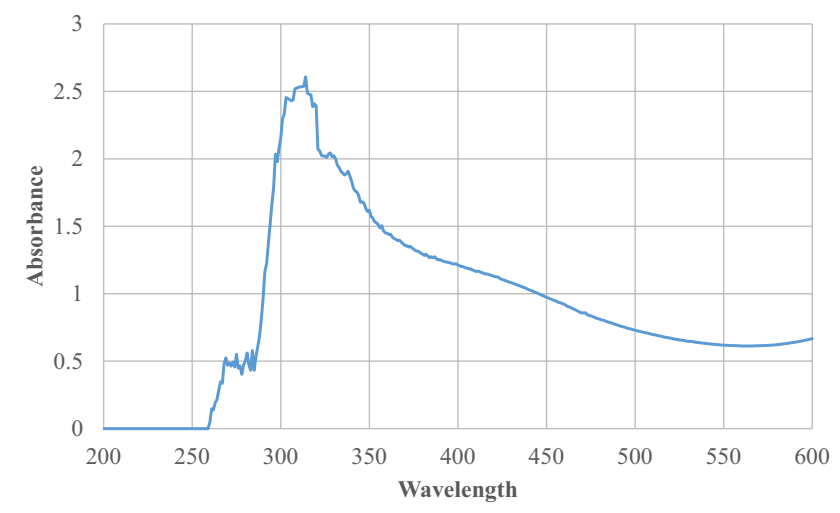

Fig. 1 UV-Vis spectra of biosynthesized ZnO-NPs synthesized from Ocimum americanum

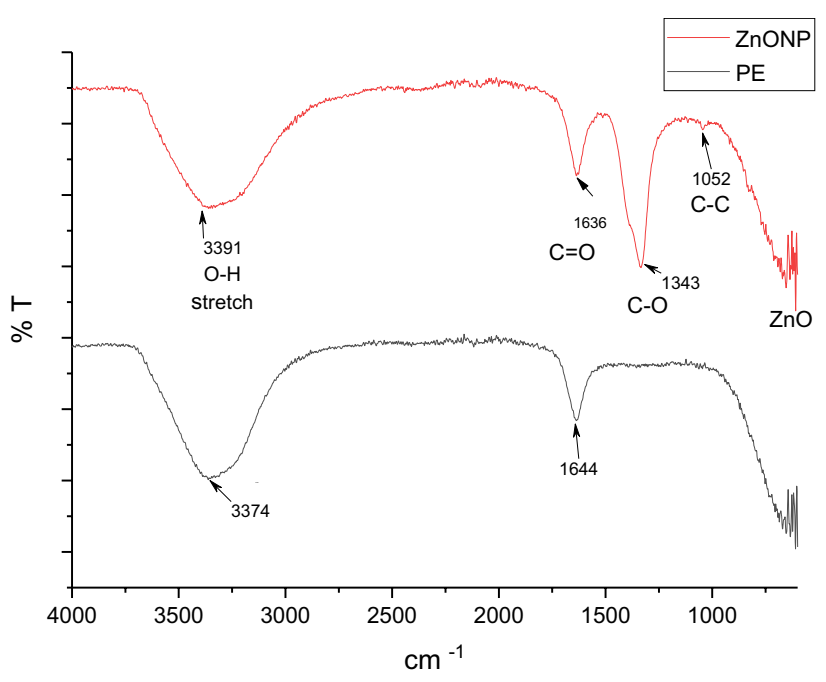

Fig. 2 FTIR spectra of Ocimum americanum extract and their biosynthesized $\mathrm{ZnO}-\mathrm{NPs}$

determined by F values $(p \leq 0.05)$. Tukey's HSD test separated treatment means for the analysis.

\section{Results and discussion}

\subsection{Characterization of the biosynthesized $\mathrm{ZnO}$ nanoparticles}

\subsubsection{Optical characterization by UV-Visible absorption}

The preliminary confirmation of nanoparticles was confirmed by visual observation of color change. The synthesis 
was later confirmed by using UV-Visible spectroscopy for the wavelength range of $200-600 \mathrm{~nm}$ at $1 \mathrm{~nm}$ range interval $[37,38]$. The absorption maxima were observed in the range $280-330 \mathrm{~nm}$ with a strong peak at $316 \mathrm{~nm}$ (Fig. 1) which is in accordance with previous studies [38].

\subsubsection{FTIR}

The FT-IR spectrum of plant extract and synthesized nanoparticles were recorded from 4000 to $600 \mathrm{~cm}^{-1}$ by ATR method with a resolution of $4 \mathrm{~cm}^{-1}$ and 50 scans. Spectroscopic sample measurements were carried out on a Spectrum two FT-IR spectrometer. The FT-IR of plant extract and biosynthesized zinc oxide nanoparticles are given in Fig. 2. FT-IR study revealed the possible functional groups involved in the reduction and capping. The FTIR spectrum was recorded for the determination of functional groups which led to the formation of $\mathrm{ZnO}$ NP. Broad peaks at 3374 and $1644 \mathrm{~cm}^{-1}$ show the presence of $\mathrm{O}-\mathrm{H}$ stretch and hydrogen bonded groups in alcohol, phenol or water molecules in the extract [35]. A strong absorption peak at $1636 \mathrm{~cm}^{-1}$ indicates that the stretching vibration of hydroxyl (or) carboxyl groups on the surface of the ZnO NP $[39,40]$. The metal oxide vibrational peaks denote in between 600 and $400 \mathrm{~cm}^{-1}$. The peak $1343 \mathrm{~cm}^{-1}$ indicates the asymmetric stretching vibration of nitrate ions [40]. The action of $\mathrm{ZnO} N \mathrm{~N}$ synthesis and stabilization by capping might be due to the coordination of $\mathrm{ZnO}$ NPs with $-\mathrm{OH}$ and $\mathrm{C}-\mathrm{O}$ groups.

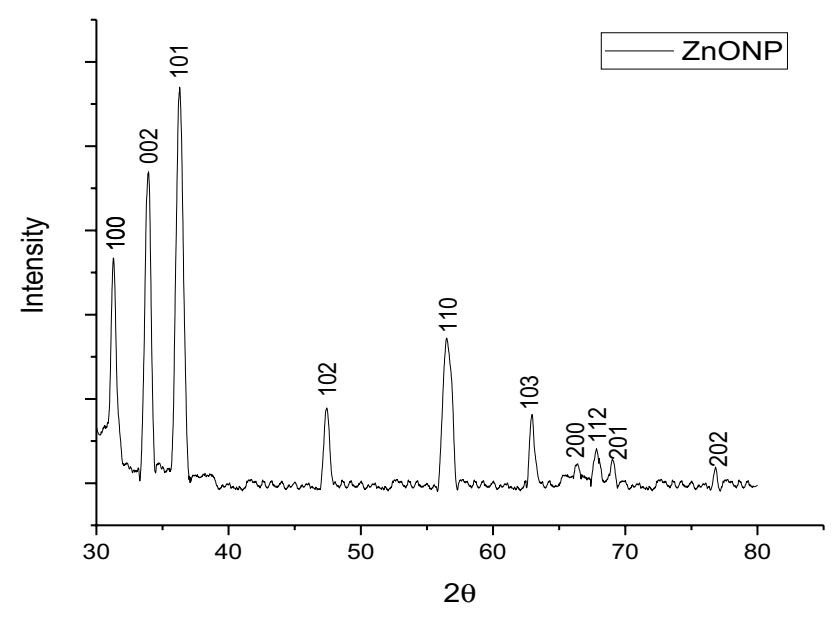

Fig. 3 X-ray diffraction spectrum of biosynthesized ZnO NPs from Ocimum americanum

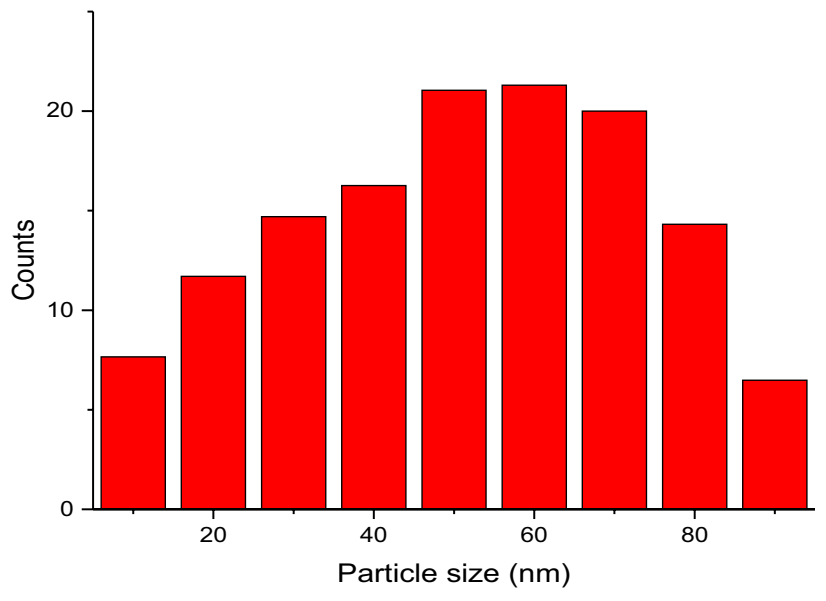

Fig. 4 Particle size of biosynthesized ZnO-NPs from Ocimum americanum by DLS analysis method

\subsubsection{X-ray diffraction (XRD) analysis}

The XRD pattern of ZnO NP confirms their spherical structure. In XRD pattern, diffraction angles are $31.61^{\circ}$, $34.23^{\circ}, 36.35^{\circ}, 47.63^{\circ}, 56.32^{\circ}, 62.79^{\circ}, 66.97^{\circ}, 67.02^{\circ}$, $69.37^{\circ}$, and $76.18^{\circ}$ which corresponding to reflection planes are 100, 002, 101, 102, 110, 103, 200, 112, 201, and 202 (Fig. 3). The obtained peaks matching with the JCPDS card no. 36-1451 confirming the ZnO (spherical structure) without any impurities [41, 42]. Sharp and narrow diffraction peaks indicate the pure crystalline nature of the material.

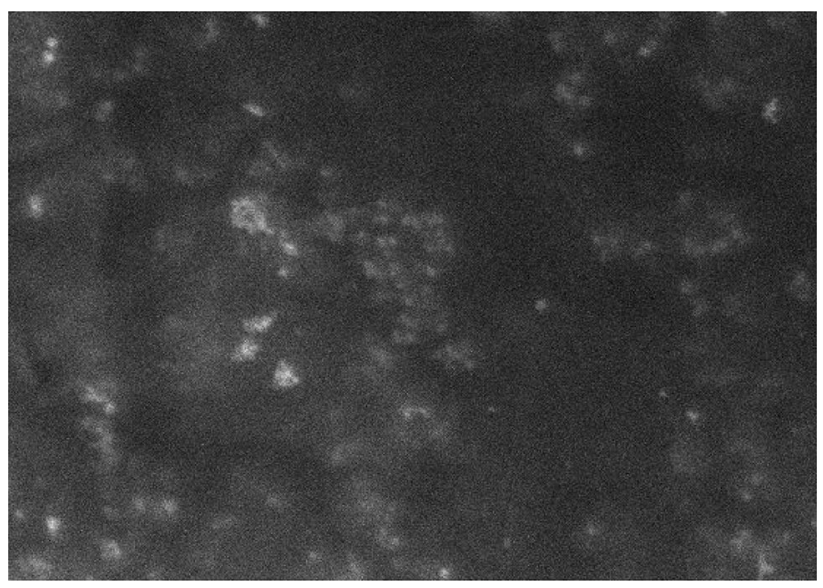

Fig. 5 Scanning electron microscopic analysis of biosynthesized ZnO-NPs from Ocimum americanum 


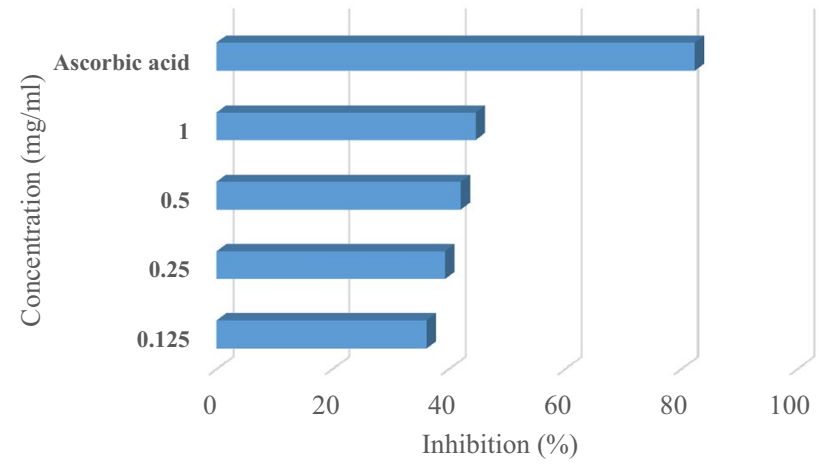

Fig. 6 Determination of anti-oxidant activity of biosynthesized ZnO-NPs from Ocimum americanum

\subsubsection{DLS analysis and zeta potential}

The particle size distribution is depicted in Fig. 4 as the histogram obtained from DLS analysis plot using origin [43]. The DLS analysis revealed particles size of an average diameter of $21 \mathrm{~nm}$ in aqueous colloidal solution. The zeta potential was found to be $12.6 \mathrm{mV}$ which has positive polarity $[26,44]$.

\subsubsection{SEM}

The morphology of biosynthesized of ZnO NPs were found to be spherical in shape with results observed from SEM micrograph (Fig. 5) at resolution of $1 \mu \mathrm{M}$ [45].

\subsection{Anti-oxidant activity}

DPPH assay serves as a rapid method for determining free radical scavenging activity. The color change occurs from purple to yellow when reduction occurs, which is quantified by determining its absorbance at $517 \mathrm{~nm}[26,46$, 47]. There was significant increase of free radical scavenging activity observed with increase in ZnO NPs (Fig. 6) (0.125 mg/mL-36.12\%; 0.25 mg/mL-39.3\%; 0.5 mg/ $\mathrm{mL}-42.01 \%$ and $1 \mathrm{mg} / \mathrm{mL}-44.57 \%)$.

\subsection{Antimicrobial activity by disc diffusion assay}

The aqueous extract of Ocimum americanum and the biosynthesized ZnO NPs were further subjected for their potential to inhibit test bacterial and fungal pathogens by disc diffusion method [48, 49]. The antimicrobial activity results showed significant inhibition against test pathogens. The highest inhibition was observed for ZnONPs against Kleibseilla pneumonia (33 mm) followed by Escherichia coli (31 mm), Bacillus cereus $(30 \mathrm{~mm})$, Staphylococcus aureus (29 mm), Pseudomonas aeruginosa (27 mm), Xanthomonas citri $(27 \mathrm{~mm})$ and Vibrio parahaemolyticus $(25 \mathrm{~mm})$. On the other hand, the maximum zone of inhibition against pathogenic fungi were observed in Aspergillus parasiticus ( $42 \mathrm{~mm}$ ) followed by Candida albicans (32 mm) (Fig. 7, Table 1). The aqueous plant extract and $\mathrm{ZnO}$ did not exhibit any antimicrobial activity. The results observed revealed high susceptibility to ZnO NPs against pathogenic fungi when compared to bacteria. The synthesized ZnO NPs were found to be stable when stored for three days at room temperature. Later, the synthesized ZnO NPs were reassessed for their biopotential, but no drastic changes were observed in their efficacy. The possible mode of action could be due to the cell membrane damage, DNA damage due to reactive oxygen species (ROS), disruption of ATP production in turn affecting DNA replication [50-52].

\subsection{Live and dead cell analysis}

The selective staining using fluorescent dye solution of ethidium bromide (EB) and acridine orange $(A O)$ revealed morphological changes occurred in live and dead cells [26]. The bacterial cell suspensions were treated with biosynthesized ZnO NPs. Gentamicin showed the presence of more dead cells when compared to untreated cells (Fig. 8). 


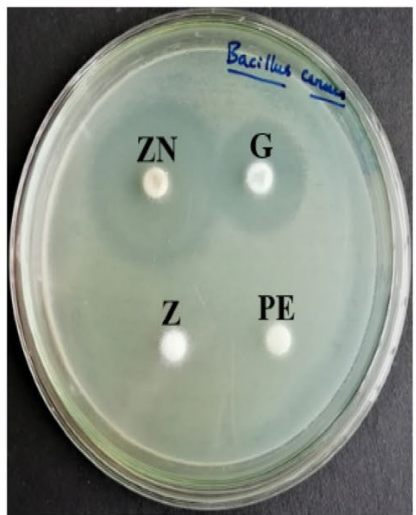

Bacillus cereus

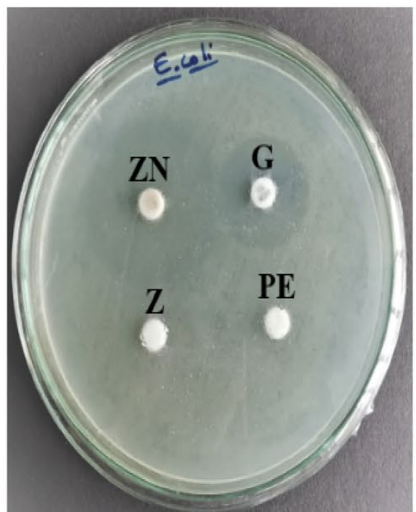

Escherichia coli

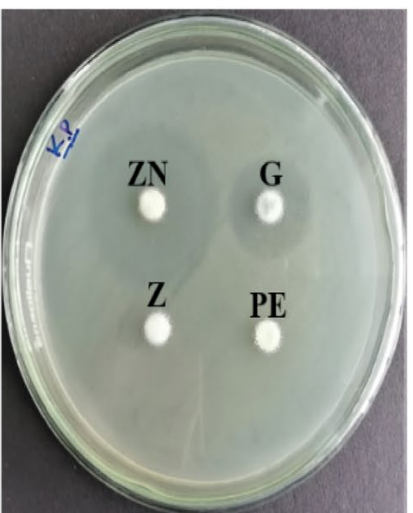

Klebsiella pneumonia

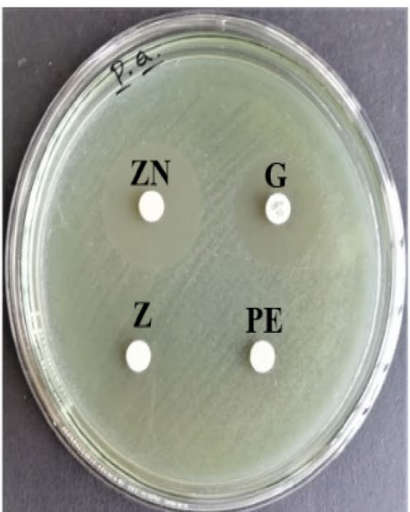

Pseudomonas aeruginosa

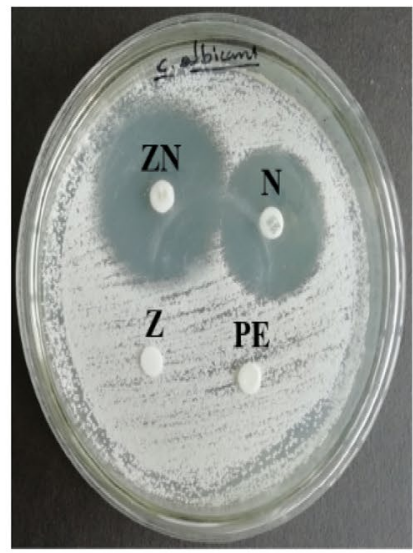

Candida albicans

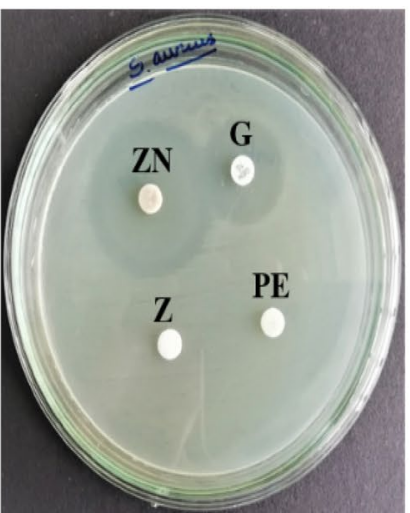

Staphylococcus aureus

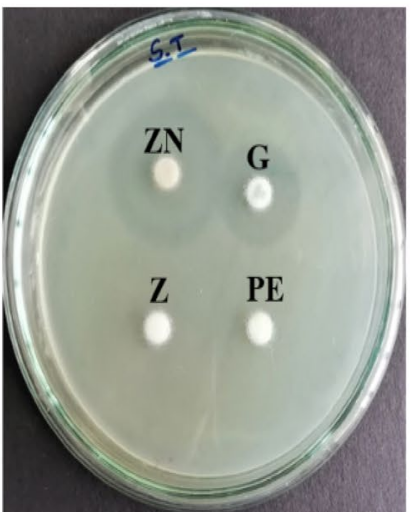

Salmonella typhi

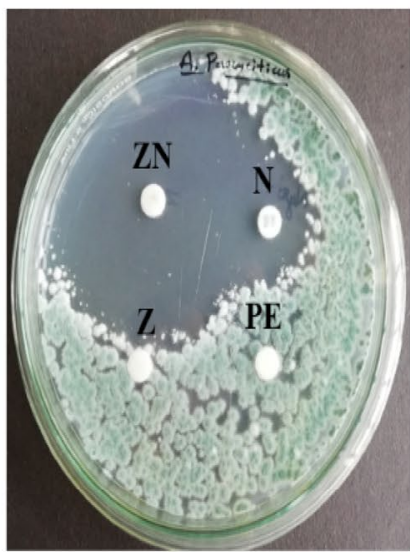

Aspergillus parasiticus

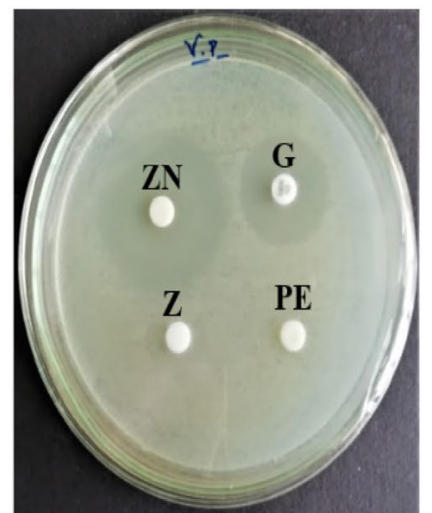

Vibrio parahaemolyticus

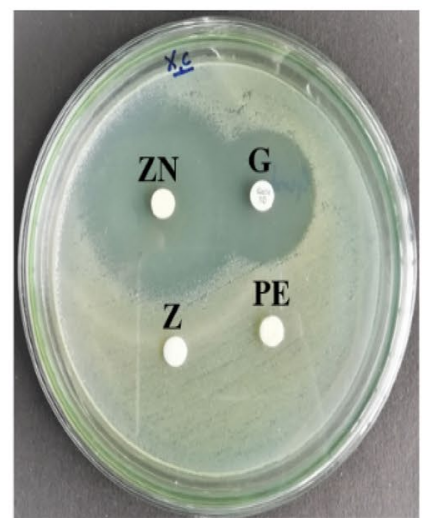

Xanthomonas citri

Fig. 7 Evaluation of antimicrobial activity of biosynthesized ZnO-NPs from Ocimum americanum by disc diffusion assay (ZN biosynthesized ZnO-NPs, PE Aqueous plant extract, Z Bulk Zinc oxide, G Gentamicin, N Nystatin) 
Table 1 Determination of antimicrobial activity of biosynthesized ZnO-NPs from Ocimum americanum by disc diffusion assay

\begin{tabular}{|c|c|c|c|c|}
\hline Organism & Gentamicin $10 \mu \mathrm{g} \mathrm{disc}^{-1}$ & $\mathrm{ZnO} N \mathrm{NP}$ & Plant extract & Zinc nitrate \\
\hline \multicolumn{5}{|l|}{ Gram positive bacteria } \\
\hline Bacillus cereus & $17.67 \pm 0.58^{d}$ & $30.33 \pm 0.58^{\text {de }}$ & NIL & NIL \\
\hline Klebsiella pneumonia & $14.33 \pm 0.58^{\mathrm{e}}$ & $33.67 \pm 0.58^{\mathrm{b}}$ & NIL & NIL \\
\hline Staphylococcus aureus & $14.67 \pm 0.58^{\mathrm{e}}$ & $29.33 \pm 0.58^{\mathrm{ef}}$ & NIL & NIL \\
\hline Vibrio parahaemolyticus & $19.67 \pm 0.58^{b c}$ & $25.67 \pm 0.58^{h}$ & NIL & NIL \\
\hline \multicolumn{5}{|l|}{ Gram negative bacteria } \\
\hline Escherichia coli & $17.67 \pm 0.58^{d}$ & $31.33 \pm 0.58^{\mathrm{cd}}$ & NIL & NIL \\
\hline Pseudomonas aeruginosa & $18.33 \pm 0.58^{\mathrm{cd}}$ & $27.67 \pm 0.58^{\mathrm{fg}}$ & NIL & NIL \\
\hline Salmonella typhi & $18.67 \pm 0.58^{\mathrm{cd}}$ & $23.67 \pm 0.58^{i}$ & NIL & NIL \\
\hline \multirow[t]{2}{*}{ Xanthomonas citri } & $18.33 \pm 0.58^{\mathrm{cd}}$ & $27.67 \pm 0.58^{\mathrm{fg}}$ & NIL & NIL \\
\hline & Nystatin $100 \mathrm{U} \mathrm{disc}^{-1}$ & ZnO NP & Plant extract & Zinc nitrate \\
\hline \multicolumn{5}{|l|}{ Dermatophyte fungi } \\
\hline Candida albicans & $28.67 \pm 0.58^{\mathrm{bc}}$ & $32.67 \pm 0.58^{\mathrm{a}}$ & NIL & NIL \\
\hline \multicolumn{5}{|l|}{ Filamentous fungi } \\
\hline Aspergillus parasiticus & $18.67 \pm 0.58^{\mathrm{cd}}$ & $42.67 \pm 1.15^{\mathrm{a}}$ & NIL & NIL \\
\hline
\end{tabular}

Values given are means of triplicates \pm SD of the mean (SEM; significant $p<0.001$ ) by one-way ANOVA. Values followed by the same superscript letter(s) within columns are significantly different at $p<0.05$ by Tukey's post hoc test

\section{Escherichia coli}

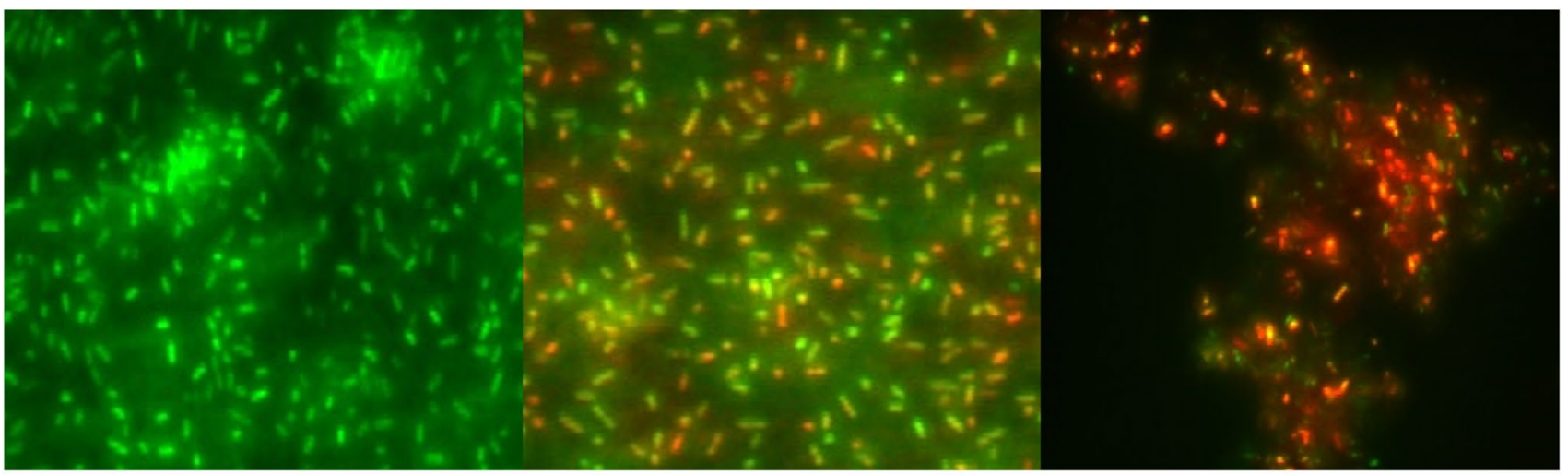

Control

Treatment with ZNP's

Treatment with Gentamicin

\section{Staphylococcus aureus}

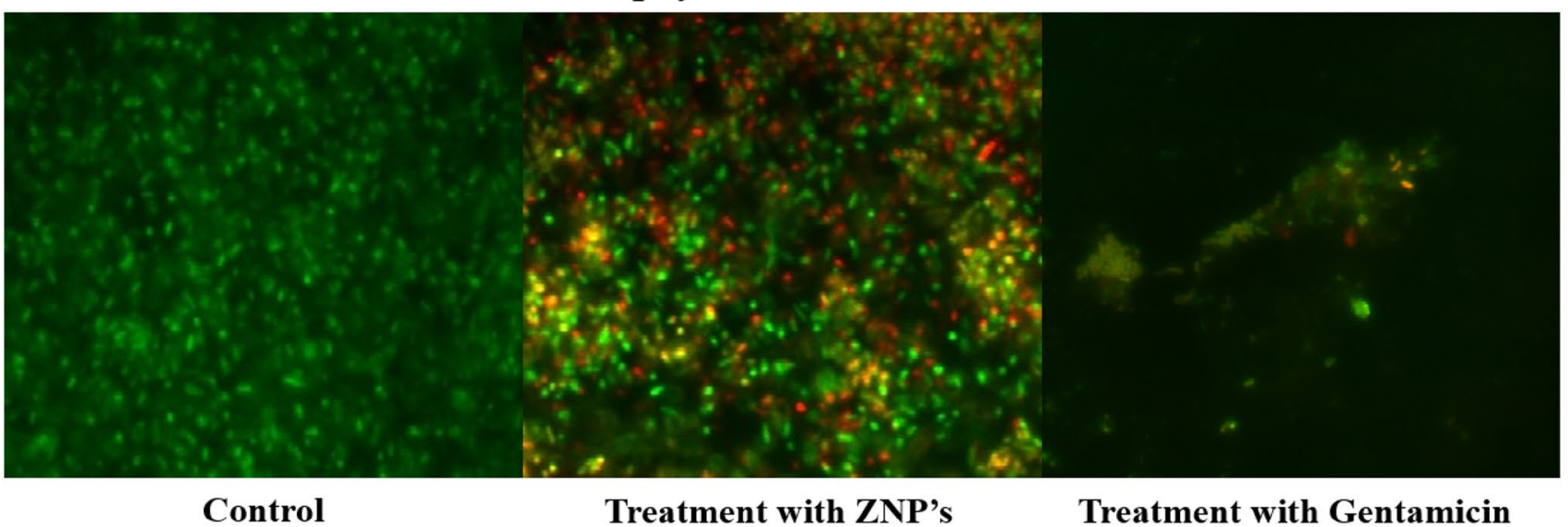

Fig. 8 Fluorescent Live and dead cells of Gram positive and Gram negative bacteria treated with ZnO NPs 


\section{Conclusions}

The green synthesis of ZnO NPs using Ocimum americanum was found to be economical, rapid, eco-friendly with potent antioxidant and antimicrobial activities. The biosynthesized ZnO NPs showed characteristic UV-Visible absorption peak at $316 \mathrm{~nm}$. Further, characterization of ZnO NPs were carried out by FT-IR, XRD, SEM and DLS analysis. UV-Vis absorption spectroscopy analysis indicated a strong absorption maximum at $316 \mathrm{~nm}$, confirming the biosynthesis of ZnO NPs. SEM revealed spherical shaped nanoparticles and XRD confirmed the crystalline nature. The present study revealed bio-fabricated ZnO NPs are more significant with potent antimicrobial activity against Gram-positive, Gram- negative and fungal pathogens.

Acknowledgements The authors would like to thank Dr. Yashavantha Rao H.C, Department of Biochemistry, Indian Institute of Science, Bengaluru, Karnataka-560012, India and Dr. Vanitha N.M, Department of Microbiology, St. Joseph's College (Autonomous), Bengaluru, Karnataka-560027, India for their help in English editing. The authors are grateful to University with Potential for Excellence (UPE) and Institution of Excellence (IOE), Department of Studies in Microbiology, University of Mysore, Mysuru for providing the necessary facilities.

\section{Compliance with ethical standards}

Conflicts of interest The authors declare that they have no conflict of interest.

\section{References}

1. Mittal AK, Chisti Y, Banerjee UC (2013) Synthesis of metallic nanoparticles using plant extracts. Biotechnol Adv 31(2):346-356

2. Yuvakkumar R, Suresh J, Nathanael AJ, Sundrarajan M, Hong SI (2014) Novel green synthetic strategy to prepare ZnO nanocrystals using rambutan (Nephelium lappaceum L.) peel extract and its antibacterial applications. Mater Sci Eng, C 41:17-27

3. Sirelkhatim A, Mahmud S, Seeni A, Kaus NHM, Ann LC, Bakhori SKM, Mohamad D (2015) Review on zinc oxide nanoparticles: antibacterial activity and toxicity mechanism. Nano-Micro Lett $7(3): 219-242$

4. Ghotekar S (2018) A review on plant extract mediated biogenic synthesis of $\mathrm{CdO}$ nanoparticles and their recent applications. Asian J Green Chem 3:125-287

5. Fardood ST, Ramazani A, Asiabi PA, Joo SW (2018) A novel green synthesis of copper oxide nanoparticles using a Henna extract powder. J Struct Chem 59(7):1737-1743

6. Fardood ST, Ramazani A, Moradi S, Asiabi PA (2017) Green synthesis of zinc oxide nanoparticles using Arabic gum and photocatalytic degradation of direct blue 129 dye under visible light. J Mater Sci: Mater Electron 28(18):13596-13601

7. Sorbiun M, Mehr ES, Ramazani A, Fardood ST (2018) Green synthesis of zinc oxide and copper oxide nanoparticles using aqueous extract of oak fruit hull (jaft) and comparing their photocatalytic degradation of basic violet 3. Int J Environ Res 12(1):29-37

8. Fardood ST, Ramazani A, Moradi S (2017) Green synthesis of Ni$\mathrm{Cu}-\mathrm{Mg}$ ferrite nanoparticles using tragacanth gum and their use as an efficient catalyst for the synthesis of polyhydroquinoline derivatives. J Sol-Gel Sci Technol 82(2):432-439

9. Seifi Mansour S, Ezzatzadeh E, Safarkar R (2019) In vitro evaluation of its antimicrobial effect of the synthesized $\mathrm{Fe}_{3} \mathrm{O}_{4}$ nanoparticles using Persea Americana extract as a green approach on two standard strains. Asian J Green Chem 3:353-365

10. Fardood ST, Ramazani A, Joo SW (2017) Sol-gel synthesis and characterization of zinc oxide nanoparticles using black tea extract. J Appl Chem Res 11(4):8-17

11. Fardood ST, Golfar Z, Ramazani A (2017) Novel sol-gel synthesis and characterization of superparamagnetic magnesium ferrite nanoparticles using tragacanth gum as a magnetically separable photocatalyst for degradation of reactive blue 21 dye and kinetic study. J Mater Sci: Mater Electron 28(22):17002-17008

12. Atrak K, Ramazani A, Fardood ST (2018) A novel sol-gel synthesis and characterization of $\mathrm{MgFe}_{2} \mathrm{O}_{4} @ \gamma-\mathrm{Al}_{2} \mathrm{O}_{3}$ magnetic nanoparticles using tragacanth gel and its application as a magnetically separable photocatalyst for degradation of organic dyes under visible light. J Mater Sci: Mater Electron 29(8):6702-6710

13. Fardood ST, Ramazani A, Moradi S (2017) A novel green synthesis of nickel oxide nanoparticles using Arabic gum. Chem J Mold 12(1):115-118

14. Atrak, K., Ramazani, A., \& Taghavi Fardood, S. (2019). Green synthesis of $\mathrm{Zn}_{0.5} \mathrm{Ni}_{0.5} \mathrm{AlFeO}_{4}$ magnetic nanoparticles and investigation of their photocatalytic activity for degradation of reactive blue 21 dye. Environ Technol. https://doi.org/10.1080/09593 330.2019.1581841

15. Moradi S, Fardood ST, Ramazani A (2018) Green synthesis and characterization of magnetic $\mathrm{NiFe}_{2} \mathrm{O}_{4} @ \mathrm{ZnO}$ nanocomposite and its application for photocatalytic degradation of organic dyes. J Mater Sci: Mater Electron 29(16):14151-14160

16. Sorbiun M, Mehr ES, Ramazani A, Fardood ST (2018) Biosynthesis of $\mathrm{Ag}, \mathrm{ZnO}$ and bimetallic $\mathrm{Ag} / \mathrm{ZnO}$ alloy nanoparticles by aqueous extract of oak fruit hull (Jaft) and investigation of photocatalytic activity of $\mathrm{ZnO}$ and bimetallic $\mathrm{Ag} / \mathrm{ZnO}$ for degradation of basic violet 3 dye. J Mater Sci: Mater Electron 29(4):2806-2814

17. Mehr ES, Sorbiun M, Ramazani A, Fardood ST (2018) Plantmediated synthesis of zinc oxide and copper oxide nanoparticles by using ferulago angulata (schlecht) boiss extract and comparison of their photocatalytic degradation of Rhodamine $B(\mathrm{RhB})$ under visible light irradiation. J Mater Sci: Mater Electron 29(2):1333-1340

18. Ghandehari F, Fani M, Rezaee M (2018) Biosynthesis of iron oxide nanoparticles by cytoplasmic extract of bacteria lactobacillus fermentum. J Med Chem Sci 1:28-30

19. Torabian $P$, Ghandehari F, Fatemi M (2018) Biosynthesis of iron oxide nanoparticles by cytoplasmic extracts of bacteria lactobacillus casei. Asian J Green Chem 2(3) pp 171-280, 181-188

20. Fardood ST, Ramazani A, Joo SW (2018) Eco-friendly synthesis of magnesium oxide nanoparticles using arabic Gum. J Appl Chem Res 12(1):8-15

21. Fan Z, Lu JG (2005) Zinc oxide nanostructures: synthesis and properties. J Nanosci Nanotechnol 5(10):1561-1573

22. Singh SC, Singh DP, Dubey PK, Tiwari RS, Srivastava ON (2014) Metal oxide nanostructures; synthesis, characterizations and applications. e-book available on internet, p. 16

23. Vijayakumar S, Mahadevan S, Arulmozhi P, Sriram S, Praseetha PK (2018) Green synthesis of zinc oxide nanoparticles using Atalantia monophylla leaf extracts: characterization and antimicrobial analysis. Mater Sci Semicond Process 82:39-45

24. Anbuvannan M, Ramesh M, Viruthagiri G, Shanmugam N, Kannadasan N (2015) Synthesis, characterization and photocatalytic activity of ZnO nanoparticles prepared by biological method. Spectrochim Acta Part A Mol Biomol Spectrosc 143:304-308 
25. Gunalan S, Sivaraj R, Rajendran V (2012) Green synthesized ZnO nanoparticles against bacterial and fungal pathogens. Prog Nat Sci: Mater Int 22(6):693-700

26. Mahendra C, Murali M, Manasa G, Ponnamma P, Abhilash MR, Lakshmeesha TR, Sudarshana MS (2017) Antibacterial and antimitotic potential of bio-fabricated zinc oxide nanoparticles of Cochlospermum religiosum (L.). Microb Pathog 110:620-629

27. Nagajyothi PC, Cha SJ, Yang IJ, Sreekanth TVM, Kim KJ, Shin HM (2015) Antioxidant and anti-inflammatory activities of zinc oxide nanoparticles synthesized using Polygala tenuifolia root extract. J Photochem Photobiol, B 146:10-17

28. Sorbiun M, Shayegan Mehr E, Ramazani A, Mashhadi Malekzadeh A (2018) Biosynthesis of metallic nanoparticles using plant extracts and evaluation of their antibacterial properties. Nanochem Res 3(1):1-16

29. Suresh D, Nethravathi PC, Rajanaika H, Nagabhushana $H$, Sharma SC (2015) Green synthesis of multifunctional zinc oxide ( $\mathrm{ZnO})$ nanoparticles using Cassia fistula plant extract and their photodegradative, antioxidant and antibacterial activities. Mater Sci Semicond Process 31:446-454

30. Chen X, Huang X, Zheng C, Liu Y, Xu T, Liu J (2015) Preparation of different sized nano-silver loaded on functionalized graphene oxide with highly effective antibacterial properties. J Mater Chem B 3(35):7020-7029

31. Hameed ASH, Karthikeyan C, Ahamed AP, Thajuddin N, Alharbi NS, Alharbi SA, Ravi G (2016) In vitro antibacterial activity of $\mathrm{ZnO}$ and $\mathrm{Nd}$ doped $\mathrm{ZnO}$ nanoparticles against ESBL producing Escherichia coli and Klebsiella pneumoniae. Sci Rep 6:24312

32. Khare CP (2008) Indian medicinal plants: an illustrated dictionary. Springer, Berlin

33. Pattanayak P, Behera P, Das D, Panda SK (2010) Ocimum sanctum Linn. A reservoir plant for therapeutic applications: an overview. Pharmacogn Rev 4(7):95

34. Louis H, Adejoke H, Amusan OO (2019) A review on classes, extraction, purification and pharmaceutical importance of plants alkaloid. J Med Chem Sci 2(4):126-170, 130-139

35. Akinmoladun AC, Ibukun EO, Afor E, Obuotor EM, Farombi EO (2007) Phytochemical constituent and antioxidant activity of extract from the leaves of Ocimum gratissimum. Sci Res Essays 2(5):163-166

36. Syed B, Bisht N, Bhat PS, Prasad A, Dhananjaya BL, Satish S, Prasad N (2017) Phytogenic synthesis of nanoparticles from Rhizophora mangle and their bactericidal potential with DNA damage activity. Nano-Struct Nano-Objects 10:112-115

37. Talam S, Karumuri SR, Gunnam N (2012) Synthesis, characterization, and spectroscopic properties of $\mathrm{ZnO}$ nanoparticles. ISRN Nanotechnol 2012:372505

38. Babu KS, Reddy AR, Sujatha C, Reddy KV (2013) Optimization of UV emission intensity of $\mathrm{ZnO}$ nanoparticles by changing the excitation wavelength. Mater Lett 99:97-100

39. Singh A, Singh NB, Hussain I, Singh H, Yadav V, Singh SC (2016) Green synthesis of nano zinc oxide and evaluation of its impact on germination and metabolic activity of Solanum lycopersicum. J Biotechnol 233:84-94
40. Das S, Sinha S, Suar M, Yun SI, Mishra A, Tripathy SK (2015) Solarphotocatalytic disinfection of Vibrio cholerae by using Ag@ ZnO core-shell structure nanocomposites. J Photochem Photobiol, B 142:68-76

41. Wahab R, Ansari SG, Seo HK, Kim YS, Suh EK, Shin HS (2009) Low temperature synthesis and characterization of rosette-like nanostructures of $\mathrm{ZnO}$ using solution process. Solid State Sci 11(2):439-443

42. Jamdagni P, Khatri P, Rana JS (2018) Green synthesis of zinc oxide nanoparticles using flower extract of Nyctanthes arbor-tristis and their antifungal activity. J King Saud Univ-Sci 30(2):168-175

43. Powers KW, Brown SC, Krishna VB, Wasdo SC, Moudgil BM, Roberts SM (2006) Research strategies for safety evaluation of nanomaterials. Part VI. Characterization of nanoscale particles for toxicological evaluation. Toxicol Sci 90(2):296-303

44. Clogston JD, Patri AK (2011) Zeta potential measurement. Methods Mol Biol 697(433):63-70

45. Rong W, Ding W, Maedler L, Ruoff RS, Friedlander SK (2006) Mechanical properties of nanoparticle chain aggregates by combined AFM and SEM: isolated aggregates and networks. Nano Lett 6(12):2646-2655

46. Mirza AU, Kareem A, Nami SA, Bhat SA, Mohammad A, Nishat $\mathrm{N}$ (2019) Malus pumila and Juglen regia plant species mediated zinc oxide nanoparticles: synthesis, spectral characterization, antioxidant and antibacterial studies. Microbial Pathog 129:233-241

47. Keshari AK, Srivastava R, Singh P, Yadav VB, Nath G (2018) Antioxidant and antibacterial activity of silver nanoparticles synthesized by Cestrum nocturnum. J Ayurveda Integr Med. https://doi. org/10.1016/j.jaim.2017.11.003

48. Santhoshkumar J, Kumar SV, Rajeshkumar S (2017) Synthesis of zinc oxide nanoparticles using plant leaf extract against urinary tract infection pathogen. Res-Eff Technol 3(4):459-465

49. Ramesh P, Rajendran A, Meenakshisundaram M (2014) Green syntheis of zinc oxide nanoparticles using flower extract Cassia auriculata. J Nanosci Nanotechnol 2(1):41-45

50. Kaviyarasu K, Geetha N, Kanimozhi K, Magdalane CM, Sivaranjani S, Ayeshamariam A, Maaza M (2017) In vitro cytotoxicity effect and antibacterial performance of human lung epithelial cells $\mathrm{A} 549$ activity of zinc oxide doped $\mathrm{TiO}_{2}$ nanocrystals: investigation of bio-medical application by chemical method. Mater Sci Eng, C 74:325-333

51. Rasmussen JW, Martinez E, Louka P, Wingett DG (2010) Zinc oxide nanoparticles for selective destruction of tumor cells and potential for drug delivery applications. Expert Opin Drug Deliv 7(9):1063-1077

52. Reddy KM, Feris K, Bell J, Wingett DG, Hanley C, Punnoose A (2007) Selective toxicity of zinc oxide nanoparticles to prokaryotic and eukaryotic systems. Appl Phys Lett 90(21):213902

Publisher's Note Springer Nature remains neutral with regard to jurisdictional claims in published maps and institutional affiliations. 